\title{
Reseñas de publicaciones
}

\section{La lengua del turismo. Géneros discursivos y terminología}

Calvi, Maria Vittoria y Mapelli, Giovanna (Eds.), Peter Lang, Bern, 2011

ISBN 978-3-0343-1011-6

\section{Lucía Fernández Amaya}

\author{
lferama@upo.es
}

En La lengua del turismo. Géneros discursivos y terminología, las editoras Maria Vittoria Calvi y Giovanna Mapelli recopilan una gran selección de trabajos que han agrupado en dos áreas temáticas diferenciadas y complementarias: los géneros discursivos, por un lado, y el léxico y la terminología, por otro. El prestigio de las editoras, aunado al de los autores de cada uno de los capítulos, son sólo la referencia inicial de un contenido prometedor.

Tras una breve introducción donde se presentan los contenidos de los distintos capítulos, Maria Vittoria Calvi abre la primera sección con "Pautas para el análisis de los géneros discursivos". Según la autora, aunque bajo el término "turismo" se recogen numerosos textos de diversa índole destinados tanto a expertos como a usuarios, se pueden observar algunas características comunes que permiten reconocer distintos géneros. Para llevar a cabo esta observación, Calvi se basa en los resultados de un proyecto de investigación que dio como resultado el corpus bilingüe español-italiano denominado Linguaturismo, que recoge diversos géneros textuales. Este será el corpus utilizado en gran parte de los estudios presentados en este volumen, de ahí que las principales lenguas de análisis serán el español y el italiano.

Siguiendo la clasificación que propuso en 2010, Calvi (2011: 20) establece una división de los géneros utilizados en el mundo del turismo en cuatro niveles:

- familias de géneros: se definen por la comunidad profesional de origen, así como por sus objetivos principales (géneros editoriales, comerciales, institucionales, etc.);

- macrogéneros: productos tangibles, identificables por el emisor, el canal utilizado y un propósito comunicativo dominante, pero caracterizados por la hibridación de diferentes géneros (guía de turismo, página web, etc.);

- géneros: dotados de autonomía funcional y formal (guía descriptiva, itinerario, programa de viaje, etc.);

- subgéneros, con distintas articulaciones temáticas.

Además de la localización de cada género en un macrogénero o un sistema de géneros, la autora propone que para analizar en profundidad los distintos géneros turísticos es necesario tener en cuenta la influencia de los siguientes elementos: a) los factores culturales e ideológicos (estereotipos, visiones del viaje y del turismo, etc.);

b) la localización;

c) las características de las situaciones comunicativas, dándose una preponderancia de los medios escritos sobre la comunicación cara a cara, y las identidades discursivas (emisor-experto, destinatario turista o viajero, bloggers, etc.);

d) los factores estructurales (disposición de los contenidos, función de los elementos icónicos, etc.);

e) las funciones pragmáticas principales (informar, instruir y persuadir);

f) las categorías lingüísticas más recurrentes, tales como la valoración, la prescripción, la impersonalidad, etc.

En el siguiente capítulo titulado "Taxonomía de los textos turísticos: factores lingüísticos y factores culturales", Giovanna Mapelli y Sara Piccioni presentan algunos de los resultados más significativos del ya mencionado proyecto Linguaturismo, obtenidos mediante el análisis cuantitativo. Este estudio que se enmarca dentro de la

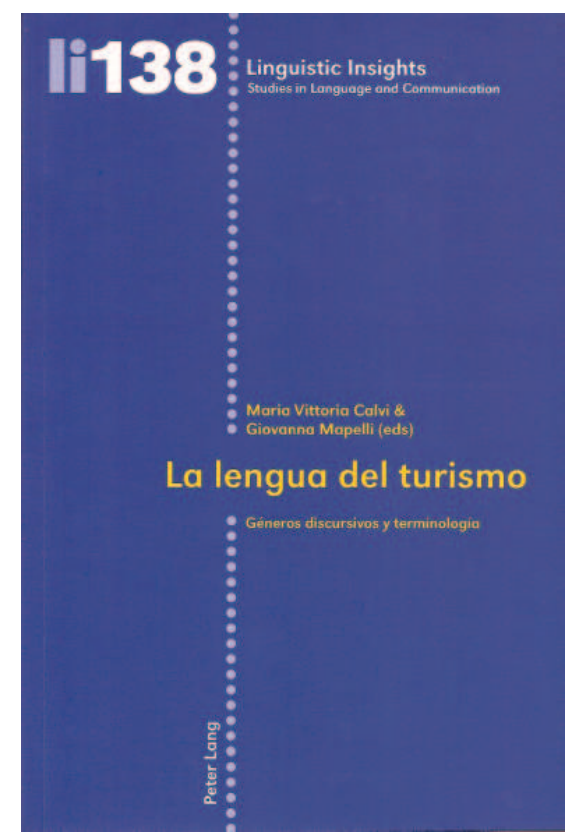


lingüística de corpus, tiene como objetivo verificar la validez de la taxonomía utilizada en la elaboración del corpus, teniendo en cuenta el distinto nivel de implicación de los participantes en cada una de las clases de textos seleccionadas. Para ello, las autoras siguiendo a Biber (2003) y Parodi (2005) establecen cinco dimensiones de variación lingüística en los textos, aunque para este estudio se centrarán en gran medida en la primera (Mapelli / Piccioni, 2011: 52):

- dimensión 1: foco contextual-interactivo, que se asocia con textos que muestran una fuerte dependencia del contexto y una activa participación de los interlocutores;

- dimensión 2. foco narrativo, que da cuenta de la sucesión cronológica de eventos;

- dimensión 3: foco compromisorio, que caracteriza a aquellos textos en los que la aparición de los interlocutores, junto con sus intenciones, es prominente;

- dimensión 4: foco modalizador, propio de aquellos textos en los que aparecen explícitamente las actitudes de los hablantes,

- dimensión 5: foco informacional, que caracteriza a textos orientados hacia la transmisión de información.

Tras la comparación del corpus español e italiano, se aprecia que los textos italianos están más cerca del polo informativo mientras que los españoles están más asociados con el foco contextual-interactivo. Así, se observa que estos últimos están más abiertos al interlocutor dada la alta presencia de elementos asociados a la dimensión interactiva (deícticos, adverbios de negación, futuro, etc.), mientras que en los documentos italianos predominan las formas impersonales y la nominalización. De cualquier forma, el estudio contrastivo permite comprobar que ambos corpus tienen una distribución parecida, pues las categorías textuales se suceden más o menos en el mismo orden, lo que indica que estos géneros serán fácilmente reconocibles en los mercados de turismo italiano y español. Finalmente, Mapelli y Piccioni concluyen que los resultados confirman la validez de la clasificación de géneros creada en el proyecto Linguaturismo y descrita en Calvi (2010), así como la definición de la lengua del turismo como lengua de especialidad.

Tras estos dos capítulos de índole más general, los ocho capítulos restantes en este primer apartado sobre géneros discursivos están dedicados al estudio de distintos géneros textuales propios del turismo. En "Guías turísticas, intertextualidad y memoria discursiva: las Guías de Italia en lengua francesa", Donella Antelmi analiza un corpus de 13 textos franceses relativos al viaje en Italia, centrándose en el prediscurso.

La autora explica que este concepto comprende las siguientes áreas: “...las bases cognitivas, los elementos de conocimiento intersubjetivo que afluyen y se construyen, o modifican, a través de la práctica discursiva relativa al turismo. Así pues, el prediscurso ${ }^{1}$ está constituido por los conocimientos adquiridos, clichés, etc., que se manifiestan en el texto, en el que se muestra la permanencia o evolución de una determinada concepción del viaje, del turista y de todo lo que le rodea" (Antelmi, 2011: 76). Tras el análisis, se puede observar que el tema más recurrente es el relativo a las riquezas culturales y destaca la persistencia de estereotipos que sobreviven a las distintas transformaciones del contexto cultural.

La guía de viajes es también el objeto de estudio del próximo capítulo ("Imágenes de Italia en las guías turísticas alemanas"), donde Francesca Santulli repasa la evolución de la imagen de Italia en algunas guías alemanas de distintas épocas: un Baedeker de 1902, una guía artística de 1977, una guía de 2006 y otras dos más recientes. La autora comienza describiendo las características principales de la guía turística, que permiten identificarla como género. A través del análisis de los distintos textos, Santulli comprueba que la elección de los rasgos textuales de la guía está determinada por las características del mercado al que va dirigida. Asimismo, el análisis permite observar que las imágenes de Italia, aunque están relacionadas con ideas comunes, varían por distintos motivos: el cambio del objeto observado (Italia), la evolución de la práctica social que llevan a cabo (el turismo) y el cambio del producto que las promociona (la guía).

En el siguiente capítulo titulado "Voces del discurso en reportajes de viajero", Jordi Canals y Elena Liverani realizan un estudio comparativo de los procedimientos de cita utilizados en una serie de reportajes españoles e italianos sobre Sicilia, tomados de las publicaciones $\mathrm{Al}$ taïr y Meridiani, respectivamente. Según los autores, la polifonía enunciativa que se observa en este género tiene varias finalidades: “...dar al lector una estampa etnogeográfica vivaz y poblada por personajes que forman parte integrante del paisaje que se describe, pero también la de incluir en el texto juicios de valor de cuya responsabilidad el autor se descarga" (Canals / Liverani, 2011: 113). Además, se recurre a secuencias argumentativas y persuasivas para intentar convencer al lector de que visite la zona descrita. Siguiendo a Ducrot (1984), Canals y Liverani explican que a través del argumento de autoridad, el locutor se distancia de la responsabilidad del contenido expresado. El lector, por su parte, no suele poner en duda la veracidad de la cita de autoridad, al considerarlo un testimonio recogido fielmente. Sin embargo, los autores avisan de que a pesar del efecto de objetividad y realidad que pueda transmitir, ninguna cita directa es neutral, ya que el simple acto de aislar unas palabras de su contexto puede dar lugar a una manipulación de la información.

En el próximo capítulo también se estudia otro género de carácter periodístico: el itinerario de viaje. En "La deíxis y la modalización discursiva en los itinerarios de viaje periodísticos", Álida Ares Ares analiza cualitativamente cuatro textos del corpus Linguaturismo. La autora observa que imperan los deícticos espaciales, ya que se trata de textos predominantemente descriptivos. El análisis además muestra que en ninguno de los textos se prescribe un orden cronológico, a pesar de que se den consejos sobre que actividades hacer a determinadas horas del día. Respecto a la modalización, resulta dominante la apreciativa, que acentúa el tono subjetivo de estos textos 
que combinan características del periodismo con otras de la lengua del turismo.

La página web es el objeto de estudio de los dos siguientes capítulos. En el primero de ellos titulado "La lengua de la promoción turística en el sitio <www.turismodecanarias.com>", Rosa María Rodríguez Abella analiza este sitio web institucional, centrándose en los códigos icónicos, los elementos léxicos y las estrategias lingüísticas de persuasión utilizados en la elaboración de la identidad de este destino. Respecto al hipertexto, la autora siguiendo a Crystal (2002), indica que el entorno digital influye en el carácter del lenguaje que se vaya a emplear. Por ejemplo, según distintos estudios sobre la manera en que las personas visualizan las páginas web, al abrirse la página inicial, la mirada se dirige primero hacia la parte superior izquierda, después hacia abajo y al final hacia la parte superior derecha, lo que influirá en la presentación de la información. Además, el proceso de lectura en pantalla es más lento que en papel, por eso los sitios con buena legibilidad presentan textos breves. En cuanto a las características de los sitios web de promoción institucional, Rodríguez Abella comenta que éstos suelen presentar una función primaria de carácter persuasivo, y una secundaria de tipo informativo. El emisor es un ente público, el destinatario es indeterminado y el canal es Internet. Por último, la información suele presentarse en bloques o secciones. Según la autora, "Todas estas convenciones posibilitan el reconocimiento de este género textual por parte de los receptores, desencadenándose así una serie de expectativas que facilitan la comprensión del mismo" (Rodríguez Abella, 2011: 158).

Por su parte, en "La persuasión a través del metadiscurso interpersonal en el género Página Web Institucional de Promoción Turística en inglés y español”, Francisca Suau Jiménez se centra en el análisis cuantitativo de las marcas de metadiscurso interpersonal en estas dos lenguas. Siguiendo la clasificación de Calvi (2010) anteriormente mencionada, la autora identifica la Página Web Institucional de Promoción Turística como un macrogénero del tercer tipo (descripción y promoción del destino turístico). En cuanto a la persuasión, Suau Jiménez indica que ésta va ligada a la función interpersonal que se expresa a través del metadiscurso. Tras su análisis, la autora comprueba que tanto en las páginas en inglés como en español se utilizan realzadores, pero sin embargo, otras categorías metadiscursivas, como los mitigadores y los marcadores de compromiso, son mucho más frecuentes en inglés que español.

En el siguiente capítulo ("Lengua e ideología: huellas polifónicas en los preámbulos de la legislación turística española”), Elena Carpi analiza el vínculo existente entre el lenguaje y la ideología en las leyes de ordenación del turismo (LOT). Usando como corpus el ya citado Linguaturismo, estudia los paratextos que preceden al cuerpo de las LOT promulgadas en las distintas Comunidades Autónomas españolas entre 1994 y 2003. Según la autora, el lenguaje que emplea el legislador suele estar relacionado con su sistema de valores, por ello, los preámbulos se redactan utilizando un registro diferente al del lenguaje normativo. Esto queda patente en el corpus analizado donde las ideas del grupo social y político que el legislador representa se traslucen a través de una gran variedad de herramientas lingüísticas tales como las estrategias valorativas y los marcadores evidenciales en la construcción de las condiciones de verdad de los enunciados.

El último capítulo de este primer apartado está dedicado al rebranding, es decir, la promoción de nuevas identidades de los lugares. Paola Catenaccio analiza en "La recalificación urbana entre (re)branding y participación social. Un enfoque discursivo" un corpus constituido por textos programáticos en inglés, basándose principalmente en los aspectos discursivos y las formas de representación de los diversos sujetos involucrados. Los textos analizados son documentos oficiales de seis proyectos de recalificación urbana de ciudades y barrios ingleses que han invertido ingentemente en proyectos de regeneración. Según la autora, el proceso de place rebranding además de implicar mejoras sociales y urbanísticas, hace referencia a operaciones de índole discursivo que contribuyen a la creación de una nueva imagen y generan las condiciones necesarias para que las intervenciones urbanísticas se lleven a cabo con participación social. Tras el análisis, se vislumbran signos léxico-sintácticos recurrentes que indican una orientación hacia el futuro: "Esta orientación se declina en dos tendencias principales: una hacia la desagentivización, orientada a representar la evolución urbana, que se plantea como no negociable e ineluctable; la segunda hacia la fuerte personalización de las instituciones que se ocupan de la recalificación, típicamente representadas como sujetos involucrados en primera persona (como demuestra el uso frecuente de la primera persona del plural) y ocupadas en acciones que se describen con un alto grado de certeza epistémica, que indica, en este caso, la definitiva naturaleza de los procesos previstos." (Catenaccio, 2011: 242).

La segunda parte del volumen recoge estudios centrados en cuestiones de léxico y terminología. En el primero de los capítulos de esta sección titulado "El glosario Linguaturismo: aplicación del enfoque de géneros a la terminología”, Javier Santos López reflexiona sobre la terminología del lenguaje del turismo y propone relacionarla con el enfoque de géneros. El autor utiliza para este capítulo las partes del corpus que considera más propias de la gestión del turismo, es decir, aquellas dedicadas a los billetes, los contratos, la información económica, la normativa y los programas de viaje. A partir de este subcorpus, Santos López elabora un glosario español-italiano cuyas entradas contienen los siguientes elementos: la equivalencia, la traducción, la categoría gramatical, el contexto, la determinación de la familia de géneros, el macrogénero y el género textual. Tras el estudio del corpus se observa que no todos los géneros resisten una elaboración terminológica ya que la dimensión vertical de su especialización no se corresponde con los requisitos exigidos en terminología. Aun así, el autor considera que la marca de género sigue siendo útil ya que resuelve problemas de sinonimia, ayu- 
da a la comprensión de culturemas y proporciona indicaciones geográficas.

El siguiente capítulo está muy vinculado a este último. En "El mapa conceptual en el glosario Linguaturismo. Metodología de elaboración y aplicaciones", Paula de Santiago González y Elena Landone llevan a cabo una descripción de los mapas conceptuales creados para el análisis terminológico y fraseológico del glosario de la gestión del turismo perteneciente al corpus Linguaturismo. Por lo tanto, una vez más los géneros textuales tenidos en cuenta son billetes, contratos, textos económicos, normativas y programas de viajes. Siguiendo a Cabré y Estopà (2002, 2005) y Guantiva, Cabré y Castellá (2008), las autoras definen la unidad que han utilizado en el análisis (unidad de conocimiento especializado, UCE) y defienden la importancia de los mapas conceptuales para el trabajo terminológico y fraseológico, ya que su elaboración es primordial para definir la especialidad, en este caso, la gestión del turismo. Como ejemplo, muestran datos relativos a la elaboración de su mapa conceptual, tales como su representación gráfica o los tipos de relaciones tenidos en cuenta.

En el capítulo sucesivo titulado "Verbos de percepción sensible e intelectual en las guías y en la publicidad turística", María Enriqueta Pérez Vázquez intenta relacionar este tipo de verbos con el lenguaje del turismo. Para ello, la autora lleva a cabo un análisis gramatical contrastivo principalmente de dos guías turísticas sobre las Rutas del Vino, ambas comparables por su temática, extensión y formato: una sobre España, Guía del turismo en España 2009 de Anaya, y otra sobre Italia, Itinerario del vino (2009) de DeAgostini. Dicho análisis se completa con distintas guías turísticas generales y diversos textos publicitarios obtenidos del corpus Linguaturismo. Pérez Vázquez (2011: 297) afirma que su estudio es pertinente puesto que “... el turismo implica una actividad en la que intervienen los sentidos, el intelecto, los conocimientos culturales y en la que por tanto resulta fundamental la percepción física e intelectual”. Tras el análisis de las guías, la autora comprueba que no existe una diferencia en cuanto a los predicados de percepción, pero sí se aprecian más verbos impersonales en italiano que en español. Por otro lado, en ambas lenguas, el uso de verbos de conocimiento es más reducido que los de movimiento y los existenciales. Respecto la comparación de estos resultados con la publicidad turística, se puede comprobar que en los anuncios hay un mayor número de verbos de percepción que en las guías. Así, mientras que en las guías el turista es dirigido a través de juicios estéticos presentados asertivamente (función prescriptiva), en los textos publicitarios predomina la función persuasiva.

El próximo capítulo ("La combinatoria preferente en los sitios web de los lugares patrimonio de la UNESCO españoles e italianos") es una descripción de las páginas web de las Ciudades patrimonio de España y de Italia. María del Carmen Navarro y Renzo Miotti comparan dichas páginas empezando por su macroestructura y analizan la naturaleza del vocabulario empleado. Así, comprueban que, dado que el vínculo existente entre el turismo cultu- ral y patrimonio material es tan estrecho, se encuentran en el corpus un gran número de palabras relacionadas con la historia del arte, aunque también aparecen numerosos términos relacionados con la gastronomía y la arquitectura. Navarro y Miotti también tienen en cuenta la descripción morfológica de las combinaciones más recurrentes. Las autoras notan que la adjetivación apreciativa es la función dominante tanto en español como en italiano, debido a que el objetivo principal de los textos analizados es apelar a los sentidos y las emociones del usuario.

En el último capítulo ("Unidad y variación en el español del turismo: las páginas web de promoción de hoteles de España y Chile”), Julia Sanmartín Sáez trata de comprobar si existen diferencias léxicas en la promoción de hoteles de España y de Chile, a través de la comparación de páginas web y normativas de turismo. La autora parte de la hipótesis inicial de que la lengua española presenta una variación geográfica que influirá en el léxico del discurso turístico. Durante el análisis, los términos de este corpus pasan por tres filtros:

1. hablante peninsular, para detectar aquellas palabras que considere extrañas;

2. se comprueba si los términos señalados aparecen en páginas web similares en España para confirmar o desmentir el primer filtro;

3. búsqueda de las voces seleccionadas en diversos diccionarios generales (DRAE, DEA...)

Tras la aplicación de los tres filtros, se observan 56 voces singulares del español chileno que se clasifican en cinco campos nocionales: categoría hotelera, habitación, servicios en el hotel, gestión hotelera e información adicional. Otro de los resultados a recalcar es el gran número de anglicismos encontrados tanto en las páginas web españolas como chilenas, aunque su presencia es aún mayor en estas últimas. En términos generales, se puede apreciar que las páginas web analizadas presentan una mayor variación léxica que la normativa oficial, lo cual es lógico si se tiene en cuenta que necesitan mostrar originalidad para atraer la atención del posible cliente. Todas ellas comparten el uso de la función persuasiva y un discurso dirigido a un público no especializado en gestión hotelera.

En mi opinión, el presente volumen supone una gran aportación para los estudios sobre la lengua del turismo, ya que presenta un panorama representativo de los distintos géneros textuales y áreas léxicas. Los trabajos presentados muestran una gran diversidad y riqueza en las perspectivas analíticas presentadas para estudiar la lengua del turismo, que van desde la lingüística de corpus al análisis del discurso. Sin duda alguna, este libro constituye una referencia obligada para todos aquellos que realizan estudios en esta área de investigación.

\section{Referencias}

\section{Biber, Douglas}

2003 "Variation among university spoken and griten registers: A new multi-dimensional análisis.” En Leciti- 
na, Pepi / Meyer, Charles (Eds) Corpus Análisis: Language structure and language use,47-70, Ámsterdam: Rodopi.

Cabré, María Teresa / Estopà, Rosa

2002 "El conocimiento especializado y sus unidades de representación: diversidad cognitiva”. Sendebar 13, 141-153.

Cabré, María Teresa / Estopà, Rosa

2005 "Unidades de conocimiento especializado: caracterización y tipología”. En Cabré, María Teresa y Bach, Carme (Eds) Conocimiento, lenguaje y discurso especializado, 78-83, Barcelona: Universitat Pompeu Fabra.

Calvi, Maria Vittoria

2010 "Los géneros discursivos en la lengua del turismo: una propuesta de clasificación”. Ibérica 19, 9-32.

Cristal, David

2002 El lenguaje e Internet. Madrid: Cambridge University Press.

Ducrot, Oswald

1984 El decir y lo dicho. Polifonía de la enunciación. Buenos Aires: Hachette.

Guantiva, Ricardo / Cabré, María Teresa / Castellá, Josep María

2008 "Clasificación de textos a partir de su terminología". Íkala, Revista de Lenguaje y Cultura 13/19, 16-39.

Parodi, Giovanni

2005 "Lingüística de corpus y análisis multidimensional: Exploración de la variación en el corpus PUCV-2003". Revista Española de Lingüística 35/1, 45-76.

\section{Notas}

1 Cursiva de la autora

Recibido:

Reenviado:

Aceptado:

$24 / 2 / 2012$

$9 / 3 / 2012$

Sometido a evaluación por pares anónimos 